\section{Applicability of thermodynamic modelling of phase-chemical composition and rheological properties for multi-component natural and technological objects}

AleXANDER SLOBODOV - St. Petersburg State Institute of Technology, Physical Chemistry Department and ITMO University (St. Petersburg), Energetics Information Technology Department - aslobd@gmail.com ALEXANDER USPENSKIY - ITMO University (St. Petersburg),

Energetics Information Technology Department - alexander_uspensky@mail.ru

SERGEY YAVSHITS - V. G. Khlopin Radium Institute (St. Petersburg), Nuclear Energy Laboratory - syavshits@gmail.com

ALEXEY MISCHENKO - St. Petersburg State Institute of Technology, Physical Chemistry Department - spbaleksey@yandex.ru

Érkezett: 2015. 08. 15. - Received: 15. 08. 2015. - http://dx.doi.org/10.14382/epitoanyag-jsbcm.2015.28

Alexander SLOBODOV is Professor at St. Petersburg State Institute of Technology, Physical Chemistry Department and at ITMO University (St. Petersburg), Energetics Information Technology Department; Doctor of Science; Member of the New York Academy of Sciences; main fields of interest: thermodynamic physico-chemical research and modeling of multicomponent natural and technological systems, mathematics methods in physical chemistry, thermodynamic databases, material science.

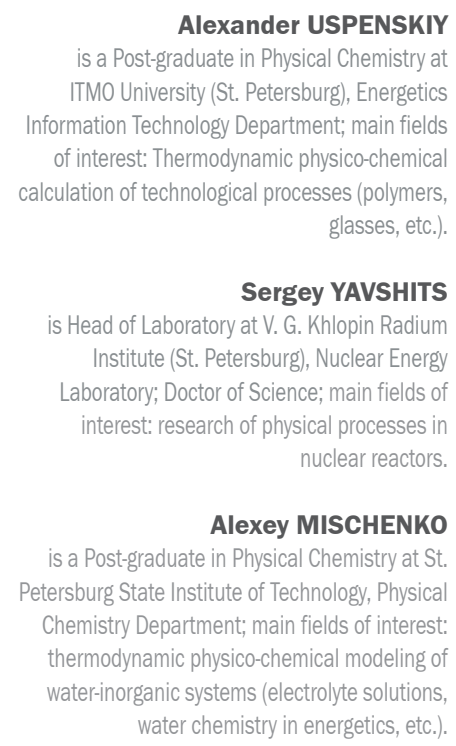

Alexander USPENSKIY is a Post-graduate in Physical Chemistry at TMO University (St. Petersburg), Energetics rmation Technology Department; main fields of interest: Thermodynamic physico-chemical glasses, etc.

Sergey YAVSHITS Head of Laboratory at V. G. Khlopin Radium Institute (St. Petersburg), Nuclear Energy aboratory; Doctor of Science; main fields of interest: research of physical processes in nuclear reactors.

\title{
Abstract
}

Thermodynamic methods and databases have been developed in this work that allow to model and calculate simultaneous phase-chemical equilibria of advanced materials with taking into account dispersion. The developed methods are unlimited with regard to number of species, components, phases, and composition of modelled system. Efficiency of the methods proposed is proved by good agreement with practically observed industrial processes along with properties of numerous synthetic and natural materials such as catalysts, silicate systems, oceanic concretes, etc.

Keywords: rheology, thermodynamics, modelling, databases, phase transformations, catalysts, silicate, radionuclides, concretes

Kulcsszavak: reológia, termodinamika, modellezés, adatbázisok, fázisátalakulások, katalizátor, szilikát, radionukleidek, betonok

\section{Formulation of the problem}

The problem of determining the phase-chemical composition of various substances and materials, the influence of state parameters on them (component composition, temperature, pressure, etc.) is fundamental task to identify and predict the rheological properties of substances and materials $[1,2]$.

This problem is particularly relevant for a wide class of rather complex composition substances (materials) obtained by various natural or technological processes (formation of rocks, mineral systems, silicate materials, glasses, etc.). In these cases external conditions (e.g. temperature, the contribution of any component, etc.) often significantly influence the direction and completeness of these processes. The determination of unknown phase-chemical composition of the substance or material (i.e. its rheological characteristics too), and optimization is very complex for both scientific and practical problems.

Thermodynamic approach (being predictive whether processes of interest are possible or not, and which are the optimal conditions to conduct them) is of use in a variety of scientific fields and industrial applications. Processes and transformations occurring in real life, e.g. in synthesis of advanced materials on industrial scale, or in natural phenomena, tend to be more complicated. In those complex processes kinetic inhibitions may occur restraining the whole process or its different stages. In such a case, factual efficiency of thermodynamic method is considerably reduced [2-4].
Kinetic limitations emerging in real phenomena may be overcome with the help of catalysts. Catalysts introduced into reactive systems withdraw the kinetic constraints, and allow reaching the maximal outcome possible. Systems with added catalysts and the retracted barriers therefore can be fully described with the efficiency and rigor characteristic to thermodynamic methods. In brief, modelling of the systems involving catalytic reactions is the most justified by thermodynamic analysis.

Large part of scientific investigations devoted to catalysis and catalytic systems covers kinetic aspects in first turn. Essentially, the kinetic efficiency of catalysts, i.e. how faster processes occur with the catalyst added to the system, is studied in the works on the subject. Practical use of catalysts, despite being helpful to achieve better yield, raises new issues that pose additional constraints, which require excessive study.

In first and foremost, catalysts are active in very definite temperature ranges at high temperature regions. This range might turn to be sub-optimal in terms of outcome of the process of interest. Therefore, the need emerges to refine the optimal reaction conditions which meet the requirements of catalytic activity. In this case, the target of modelling turns into a pure thermodynamic problem, rather than a kinetic one.

In second, catalysts are lacking selectivity. This means that these additives may involve into side interactions with reagents and products. The reason for that is thermodynamic as well. 
This raises the need to account for such effects by expanding the original system "reagents-products" into a more complex system "reagents-products-catalyst", which includes all the possible transitions and reactions. The optimal conditions should be found again in the expanded system [5-7].

In this way, adding catalysts significantly reduces kinetic barriers and gives the maximal yield, thus making modelling problem as being the most effectively solved by thermodynamic calculations. Thermodynamics applied to various computation challenges shows undeniable power in finding sought solutions.

\section{Methodology}

In this work, a methodology is offered to describe, model, and calculate physical and chemical processes occurring in multi-component arbitrary systems. The approach takes into account surface phenomena as well by considering dispersion surface properties (e.g. specific surface, surface energy, etc.) of system constituents. Such considerations are of great importance specifically to catalytic, especially heterogeneous systems and processes.

The suggested methodology considers systems as solutions (solid, liquid, or super cooled) consisting of all species which present in the system. This means that all possible conversions and transitions are taken into consideration that might occur during the process. Evolution of the methodology includes multiphase equilibrium between condensed, dispersed, and gaseous phases of the known composition and volume (or pressure).

The systems under study are treated not only as solutions, which correspond to temperatures of synthesis, but also as equilibrium heterogeneous mixtures made of individual substances, matching systems state at initial temperatures.

The developed methods are represented as an application written in Pascal, FORTRAN and PL/1. This application is unlimited with regard to number of species, components, phases, and composition of modelled system. An important feature of the application is its ability to correctly predict and evaluate both phase states, including metastable phases, and processes under changing conditions, e.g., feed composition, temperature, pressure, etc.

The basis of the approach is to take advantage of minimizing the characteristic function, corresponding to the imposed conditions. Conditions ubiquitously define this function: constant overall composition $y^{0}$, volume $\mathrm{V}$, and entropy $\mathrm{S}$ correspond to internal energy $U$; constant overall composition $y^{0}$, temperature $\mathrm{T}$, and pressure $\mathrm{P}$ correspond to Gibbs energy $G$. All these characteristic functions can be turned into each other by Legendre transformation. This transformation makes all these functions, and thus, computation problems equivalent.

The computation of equilibria under different sets of constraints is easily reduced to minimization of Lagrange $L$, that allows excluding the constraints and considering only natural limitations, such as non-negativity of substances quantities in the resulting system. The minimization problem mainly consists of solving the system of equations and inequalities. The core of this system is independent of the minimized characteristic function and is defined only by internal parameters of state:

$$
\begin{array}{ll}
\mu_{i}^{(k)}=\sum_{j=1}^{m} a_{i j} \mu_{j}, \quad(\mathrm{i}, \mathrm{k}) \in \mathrm{I}^{0}: \quad \mathrm{y}_{i}^{(k)}>0 \\
\mu_{i}^{(k)} \geq \sum_{j=1}^{m} a_{i j} \mu_{j}, \quad(\mathrm{i}, \mathrm{k}) \notin \mathrm{I}^{0}: \mathrm{y}_{i}^{(k)}=0
\end{array}
$$

$\sum_{k=1}^{r} \sum_{i=1}^{n} a_{i j} y_{i}^{(k)}=y_{j}^{o} \quad \mathrm{j}=1 . . \mathrm{m}$

where $\left.\left\{\mathrm{y}_{1}^{(\mathrm{k})}, \ldots, \mathrm{y}_{\mathrm{n}}^{(\mathrm{k})}\right\}, \mathrm{k}=1 . . \mathrm{r}\right)$ is the composition of $k$-th phase, $r$ is the number of phases, $n$ is the number of chemical species in the system which are defined by stoichiometric matrix $\left\{a_{i j}\right\}$ and original substances with number of $m$.

The conditions given by Eqs. (1) to (3) reflect the material balance, and Lagrange function $L$ minimum which is the generalized law of reacting masses. It is shown that specific constraints posed to the system, such as P, V, or S, are readily taken into account without loss of method generality described by Eqs. (1) to (3).

The iterative solving is divided into the two sub-tasks during seeking for solution: "phase" sub-task, and "chemical" sub-task. In the "phase" sub-task, the qualitative phase composition $\mathrm{I}^{0}$ is found, which gives the compounds that actually form the phase. In the "chemical" sub-task implementation, the quantitative phase composition is found, which gives the quantities of the found compounds present in the phase. Convergence criterion shows the direction to move for the direction of $L$ function descent. Sub-routines were developed to solve each sub-task and the whole problem as well.

The application developed in this work is lacking any limits either in regard of number of component, or in regard of substances nature. All the standard and high-temperature quantities necessary to evaluate system equilibrium are taken from expertise databases. These databases include the data extracted from reliable and mutually consistent sources. Also, insufficient data were computed with the most rigorous thermodynamic methods whenever it was possible.

\section{Results and discussion}

Thermodynamic modelling and optimization of the process of ammonium chloride synthesis in gaseous phase was performed with help of the application developed. It was defined how the salt dispersion, gas phase composition, partial pressures, and temperature affected the yield of the product. These evaluations allow finding the optimal synthesis conditions.

Another important issue was solved by the offered method in finding optimal conditions to produce manganese concentrate from shelf ferromanganese nodules. Upon seeking for solution, it was examined how nodules dispersion, surface properties, temperature, solution compositions, and gaseous compositions changed the yield of concentrate. This examination gave the optimal conditions to produce the concentrate depending on properties of ferromanganese nodules.

Mechanisms of phase and chemical conversions observed in carbo-thermally azotizing kaoline clay to synthesize sialons $\mathrm{Si}_{\mathrm{x}} \mathrm{Al}_{\mathrm{y}} \mathrm{O}_{z} \mathrm{~N}_{\mathrm{t}}$ were also successfully found. The influence of 
reagents on properties and quantities of impurities, the region of thermal stability of sialons, and their chemical and thermochemical stability were evaluated. The conditions of phases recrystallization have been found as well, and it was discovered that the process occurs mainly in the gaseous phase.

Investigation of the process of composite cobalt-titaniumtantalum-tungsten carbonitride synthesis proceeds turned to be a challenging task, too. With help of the methodology, this system was studied in a large temperature range of 298-3000 $\mathrm{K}$. This analysis revealed how temperature and components ratio quantitatively affected the phase transformations under the synthesis, which reactions take place in homo- and heterogeneous phases, and which intermediate and by-products are formed. The most important result of this investigation is that conditions were found that make impossible to form hazardous product $-\mathrm{W}_{2} \mathrm{C}$, which makes the composite fragile by forming the compound (W,Co) ${ }_{3} \mathrm{C}$.

The developed method resulted in rigorous, correct and efficient evaluation of numerous catalyst synthesis problems. In particular, it was modelled what is happening when ferromanganese catalysts are synthesized. Results obtained upon this computation allowed finding which phase transitions and reactions take place under conditions of agglomeration of hydrated metal nitrates. Also, it was successfully found which processes occur both in bulk phase of catalysts and in porous media over a wide range of temperature. Regions of stability of basic components of the catalyst were found by analyzing the influence of temperature and feed composition on simultaneous phase- and chemical transformations. Effectiveness of promoters and modifiers on synthesis yield has also been studied over a wide range of temperature.

Fig. 1 shows important data on phase transitions upon ferromanganese catalyst synthesis against temperature:

$273 \mathrm{~K}$ :

$$
\mathrm{Mn}\left(\mathrm{NO}_{3}\right)_{2}=\mathrm{MnO}_{2}+2 \mathrm{O}_{2}+\mathrm{N}_{2}
$$$$
4 \mathrm{Fe}\left(\mathrm{NO}_{3}\right)_{3}=2 \mathrm{Fe}_{2} \mathrm{O}_{3}+15 \mathrm{O}_{2}+6 \mathrm{~N}_{2}
$$

$380 \mathrm{~K}:$ $4 \mathrm{MnO}_{2}=2 \mathrm{Mn}_{2} \mathrm{O}_{3}+\mathrm{O}_{2}$

$1374 \mathrm{~K}:$ $6 \mathrm{Mn}_{2} \mathrm{O}_{3}=4 \mathrm{Mn}_{3} \mathrm{O}_{4}+\mathrm{O}_{2}$

$1461 \mathrm{~K}:$

$$
6 \mathrm{Fe}_{2} \mathrm{O}_{3}+2 \mathrm{Mn}_{3} \mathrm{O}_{4}=6 \mathrm{MnFe}_{2} \mathrm{O}_{4}+\mathrm{O}_{2}
$$

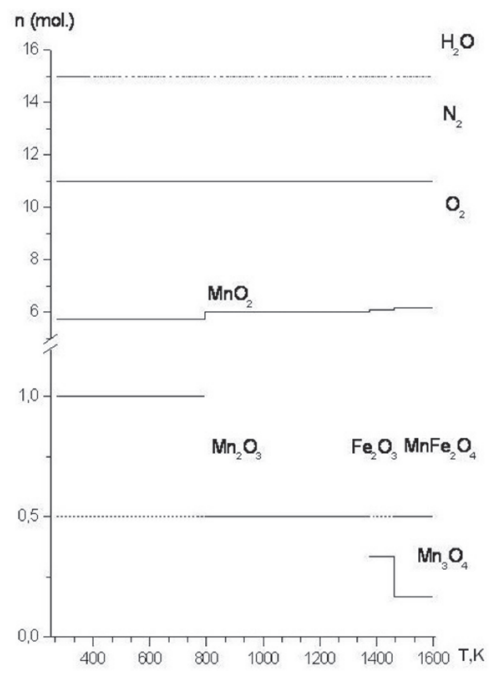

Fig. 1. Influence of temperature on phase-chemical transformations in $\mathrm{Fe}-\mathrm{Mn}$ catalysis system

1. ábra A hömérséklet hatása a fázis-kémiai átalakulásokra Fe-Mn katalizis rendszerben
Some of the data reflecting modelling results for $\mathrm{Al}-\mathrm{Cu}-$ $\mathrm{Cr}-\mathrm{O}$ catalyst synthesis are present in Fig. 2. These data illustrate how temperature influences the phase- and chemical transformations when synthesizing $\mathrm{Al}-\mathrm{Cu}-\mathrm{Cr}-\mathrm{O}$ catalyst: phase transitions points and chemical transformations of the components can be seen in the mixture:

$273 \mathrm{~K}$ :

$$
\begin{aligned}
& 2 \mathrm{CrO}_{3}=2 \mathrm{CrO}_{2}+\mathrm{O}_{2} \\
& \mathrm{Al}_{2} \mathrm{O}_{3} \cdot 3 \mathrm{H}_{2} \mathrm{O}=\mathrm{Al}_{2} \mathrm{O}_{3} \cdot \mathrm{H}_{2} \mathrm{O}+2 \mathrm{H}_{2} \mathrm{O} \\
& \mathrm{CuCO} 3+\mathrm{H}_{2} \mathrm{O}=\mathrm{Cu}(\mathrm{OH})_{2}+\mathrm{CO}_{2} \\
& \mathrm{Cu}(\mathrm{OH})_{2}=\mathrm{CuO}+\mathrm{H}_{2} \mathrm{O}
\end{aligned}
$$

$290 \mathrm{~K}:$

$426 \mathrm{~K}$ :

$493 \mathrm{~K}$ :

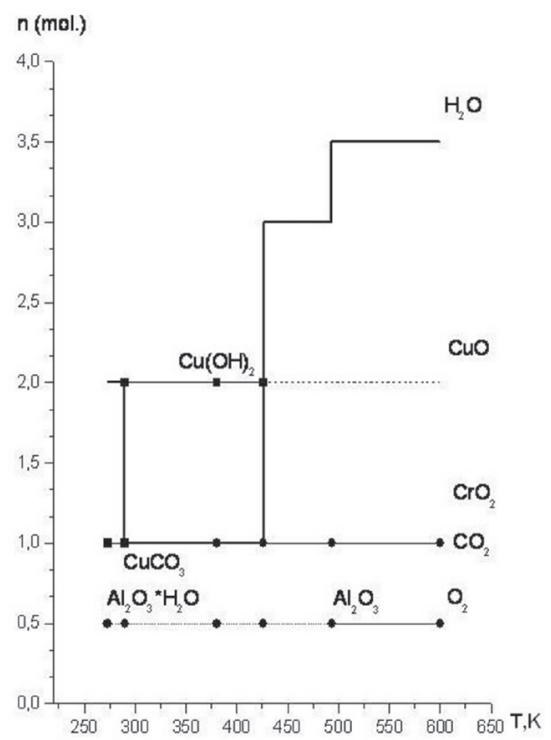

Fig. 2. Influence of temperature on phase-chemical transformations in $\mathrm{Al}-\mathrm{Cu}-\mathrm{Cr}-\mathrm{O}$ catalysis system

2. ábra A hömérséklet hatása a fázis-kémiai átalakulásokra Al-Cu-Cr-O katalizis rendszerben

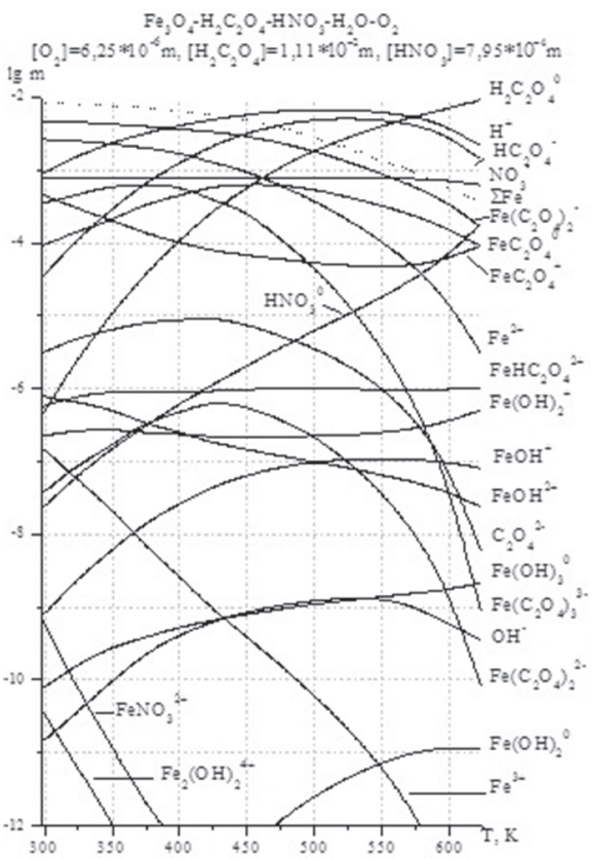

Fig. 3. Influence of temperature on water-chemical tranformations - chemical washing of corrosion products sediments

3. ábra A hőmérséklet hatása víz-kémiai átalakulásokra-korróziós üledék termékek kémiai kimosódása 
In order to study catalytic oxidation of sulphur dioxide on V-catalysts, temperature and composition influence on processes accompanying major reaction have been investigated.

The given method allows effectively solving different questions - e.g. chemical washing of corrosion products sediments on the power equipment surfaces (Fig. 3), interaction processes of radionuclides (fission products of nitride uranium-plutonium fuel) in nuclear reactors (Fig. 4) to determine optimum conditions of research processes carrying out, etc. [8-11].

On the basis of obtained physico-chemical data, it was possible to explain not only independent rheological test results, but to predict quite correctly the behaviour and rheological properties of these systems depending upon the composition and temperature.

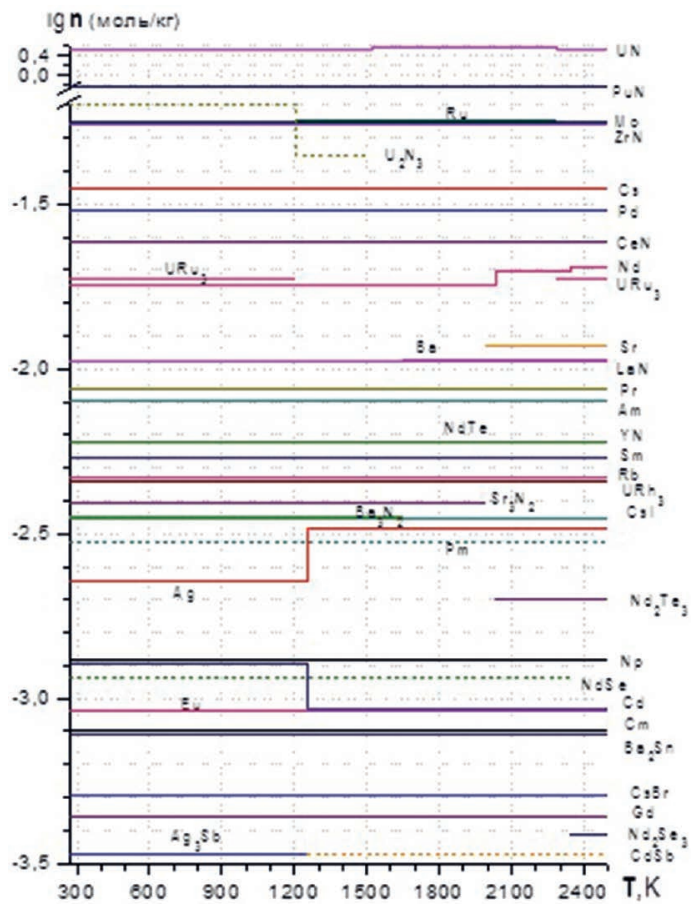

Fig. 4. Influence of temperature on phase-chemical transformations in radionuclides system - fission products of nitride uranium-plutonium fuel

4. ábra A hömérséklet hatása a fázis-kémiai átalakulásokra radionukleid rendszerben-maghasadási termékek uranium-plutónium-nitrid tüzelöanyagban

\section{Conclusions}

The results obtained theoretically and by calculation for all investigated multi-component systems not only well agreed with known experimental data (in reality, by virtue of the considered systems complexity, quite often rather fragmentary and limited), but also give qualitatively and quantitatively more information on mechanisms of running processes in complex systems of different nature, compositions and purposes.

The methodology offered in this work and its implementation give the possibility to model, calculate, and optimize numerous chemical technology processes and systems of different nature, involving such complex objects as inorganic glasses, firebricks, fluorescent dyes, organic and inorganic catalysts, processes of radionuclides, complex processes in aqueous solutions, laser processes, etc.
The application developed enables to assess certain conditions, which can be measured with great difficulties, such as extreme temperatures and pressures, by-products and impurities, and multiple components, impact system of interest. Prediction of optimal conditions is possible as a result of the development to carry out synthesis that is based on only thermodynamic methods and databases.

Calculation of phase-chemical transformations in the investigated systems allows predicting rheological characteristics of substances for different compositions in wide range of temperatures.

\section{References}

[1] Smith, W. R. (1980): Computational aspects of chemical equilibrium in complex systems. Theoretical Chemistry: Advances and Perspectives, Academic Press, pp. 185-259.

[2] Slobodov, A. A. (2002): Calculation of phase-chemical transformations in multicomponent systems of various nature on the basis of thermodynamic databank ASTIB. Proceedings XIV International Conference on Chemical Thermodynamics, St. Petersburg, pp. 471-472.

[3] Ball, J. W. - Nordstrom, D. K. (1991): User's manual for WATEQ4F with revised thermodynamic data base and test cases for calculating speciation of major, trace and redox elements in natural waters. U.S. Geological Survey, $189 \mathrm{p}$.

[4] Chase, M. W. (Ed.) (1998): NIST-JANAF Thermochemical Tables: Part I, II. ( $4^{\text {th }}$ Ed.), Journal of Physical and Chemical Reference Data, Monograph No. 9, NSRDS-AChS-AIPh, 1151 p.

[5] Zaharchenko, N. I. (2002): Catalytic Properties of the $\mathrm{Fe}_{2} \mathrm{O}_{3}-\mathrm{Bi}_{2} \mathrm{O}_{3}$ System in Ammonia Oxidation to Nitrogen Oxides. Kinetics and Catalysis. Vol. 43, No. 1, pp. 95-98. http://dx.doi.org/10.1023/A:1014209415066

[6] Leach, B. (1986): Catalysis in Industry Vol. 1. 324 p.

[7] SPbSTI(TU) (2009). Catalysis: Yesterday, Today and Tomorrow. SaintPetersburg State Institute of Technology (Technical University), 317 p.

[8] Suvorov, S. A. - Slobodov, A. A. - Bocharov, S. V. - Borzov, D. N. Matuzenko, M. Yu. (2003): Thermodynamic Simulation of the Behavior of a Carbonized Refractory. Refractories and Industrial Ceramics. Vol. 44, No. 2, pp. 84-88. http://dx.doi.org/10.1023/A:1024706909341

[9] Veiko, V. P. - Slobodov, A. A. - Odintsova, G. V. (2013): Availability of Methods of Chemical Thermodynamics and Kinetics for the Analysis of Chemical Transformations on Metal Surfaces under Pulsed Laser Action. Laser Physics. Vol. 23, No. 6, p. 066001. http://dx.doi.org/10.1088/1054-660X/23/6/066001

[10] Kritskii, V. G. - Slobodov, A. A. (2009): Predicting Growth of Deposits on Fuel Assemblies of VVER-440 Reactors. Thermal Engineering, Vol. 56, No. 5, pp. 387-389. http://dx.doi.org/10.1134/S004060150905005X

[11] Slobodov, A. A. - Yavshits, S. G. - Olekhnovich, R. O. - Sochagin, A. A. - Radin, M. A. - Sibirtsev, V. S. (2015): Completeness and Reliability of Thermodynamic Databases - Most Important Factor in Any Applications of Thermodynamic Methodology. 13th Joint European Thermodynamics Conference, JETC-2015, Book of Abstracts. ENSIC Nancy - May 20-22, 2015. pp. 244-245.

Ref.:

Slobodov, Alexander - Uspenskiy, Alexander - Yavshits, Sergey Mischenko, Alexey: Applicability of thermodynamic modelling of phase-chemical composition and rheological properties for multicomponent natural and technological objects Építőanyag - Journal of Silicate Based and Composite Materials, Vol. 67, No. 4 (2015), 164-167. p. http://dx.doi.org/10.14382/epitoanyag-jsbcm.2015.28 